\title{
FOUCAULT E LACAN: o sujeito, o saber e a verdade
}

\author{
Foucault and Lacan: the subject, the \\ knowledge and the truth
}

\author{
Luis Francisco Espíndola Camargo ${ }^{[a]}$, Fernando Aguiar $^{[b]}$ \\ [a] Graduado em Psicologia, Mestre em linguística e Doutorando em Psicologia (linha de pesquisa \\ em psicanálise) pela Universidade Federal de Santa Catarina (UFSC), Florianópolis, SC - Brasil, \\ e-mail: chicocamargo@superig.com.br \\ ${ }^{[b]}$ Doutor em Filosofia pela Université Catholique de Louvain (Bélgica), e professor no Departamento \\ de Psicologia e no Programa de Pós-Graduação em Psicologia da Universidade Federal de Santa \\ Catarina (UFSC), Florianópolis, SC - Brasil, e-mail: fabs@ cfh.ufsc.br
}

\section{Resumo}

Este trabalho visa mostrar um ponto de articulação entre o pensamento de Michel Foucault e Jacques Lacan. Este ponto está diretamente ligado a uma mesma pesquisa empreendida por ambos: a relação do sujeito com o saber e a verdade. Trata-se de uma leitura que contextualiza o seminário de Foucault $A$ Hermenêutica do Sujeito e o livro A vontade de saber com o ensino de Jacques Lacan. Os autores sustentam que as críticas dirigidas à psicanálise por Foucault perdem seu efeito quando relacionadas ao ensino de Lacan. Pretende-se demonstrar que na ocasião da publicação do primeiro volume sobre A História da Sexualidade, Lacan já havia superado os seguintes problemas apontados por Foucault: a relação da psicanálise com um dispositivo de aliança sustentado pela lei do desejo e a remissão da verdade ao mito do Édipo.

Palavras-chave: Foucault. Lacan. Sujeito. Saber. Verdade. 


\section{Abstract}

The paper focuses the articulation point between Michel Foucault and Jacques Lacan thoughts. This point is directly linked to a research undertaken by both of them: the relation between the subject and the knowledge and truth. Their research is represented by Foucault lectures The Hermeneutics of the Subject and his book The Will to Know and by the teaching of Jacques Lacan. The authors sustain that Foucault's critics to psychoanalysis loose their effects when related to Lacan's teaching. The study aims to demonstrate that at the publication of the first volume of The History of Sexuality, Lacan had already overcome the problems indicated by Foucault: the relation between the psychoanalysis and the alliance device sustained by the law of desire and the truth remission to Edipo's mith.

Keywords: Foucault. Lacan. Subject. Knowledge. Truth.

Este artigo pretende abordar um ponto de articulação entre o pensamento de Foucault e a Psicanálise. Sabe-se que a relação de Foucault com a psicanálise ao longo de toda sua obra é controversa. Muitas vezes, a psicanálise é alvo de críticas, como em A Verdade e as Formas Jurídicas e no livro A Vontade de Saber. Já em outras ocasiões recebe um lugar privilegiado, como em As Palavras e as Coisas e no curso A Hermenêutica do Sujeito.

Façamos uma distinção. A crítica de Foucault tem determinados destinatários na psicanálise. Em primeiro lugar sua crítica é direcionada aos pós-freudianos que investiram todos os seus esforços na construção de uma teoria que retoma o centro do sujeito como o próprio Eu. Toda a elaboração em torno deste pronome culmina numa psicologia do $\mathrm{Eu}$, que toma o viés contrário de um fundamento da psicanálise freudiana, a subversão do sujeito e o seu descentramento.

Num segundo momento, as críticas atingem o próprio Freud, precisamente em relação à teoria do complexo de Édipo como fundador de uma subjetividade. Já em relação a Lacan, é difícil encontrar referências negativas que denotam alguma espécie de crítica direta aos seus trabalhos. Muito pelo contrário, Foucault sempre lhe dá um lugar especial, do ponto de vista de que Lacan é alguém que está implicado no discurso de sua prática. 
Penso que o hermetismo de Lacan é devido ao fato de ele querer que a leitura de seus textos não fosse simplesmente uma "tomada de consciência" de suas idéias. Ele queria que o leitor se descobrisse, ele próprio, como sujeito de desejo, através dessa leitura. Lacan queria que a obscuridade de seus Escritos fosse a própria complexidade do sujeito, e que o trabalho necessário para compreendê-lo fosse um trabalho a ser realizado sobre si mesmo. Quanto ao "terrorismo", observarei apenas uma coisa: Lacan não exercia nenhum poder institucional. Os que o escutavam queriam exatamente escutá-lo. Ele não aterrorizava senão aqueles que tinham medo. A influência que exercemos não pode nunca ser um poder que impomos (FOUCAULT, 2002, p. 330-331).

Esta observação de Foucault exprime a intenção de Lacan de impor um estilo próprio aos seus textos, que alguns denominaram de barroco. Nesse sentido, essa citação de Foucault reafirma algo que aparece em um texto de Lacan elaborado como Abertura, em ocasião da primeira publicação da coleção Escritos no ano de 1966: "Queremos, com o percurso de que estes textos são os marcos e com o estilo que esse endereçamento impõe, levar o leitor a uma consequiência em que ele precise colocar algo de si" (LACAN, 1998, p. 11).

Tentar-se-á demonstrar aqui que essa observação de Foucault sobre o trabalho de Lacan está diretamente relacionada à problemática do sujeito com o saber e com a verdade. Na entrevista realizada em 1981 e publicada na edição brasileira da coleção Ditos e Escritos com o título Lacan, o Liberatore da Psicanálise, da qual foi retirado o extrato anterior, Foucault se posicionará junto a Lacan, haja vista que, para o primeiro, ambos estavam implicados numa mesma pesquisa empreendida a partir da leitura das obras de Lévi-Strauss. Esta pesquisa aparece na obra de Lacan como aurora do seu ensino; em Foucault, como um crepúsculo de sua obra. Próximo ao fim de sua vida, Foucault escreve que parte de seu objetivo "[...] foi criar uma história dos diferentes modos pelos quais, em nossa cultura, os seres humanos tornaram-se sujeitos"1. Este seria o ponto de articulação entre Foucault e Lacan: uma pesquisa sobre a relação do sujeito com o saber e a verdade.

[...] nós descobríamos que a filosofia e as ciências humanas viviam sobre uma concepção muito tradicional do sujeito humano, e não bastava

FOUCAULT. In: DREYFUS; RABINOW, 1995, p. 231. 
dizer, ora com uns, que o sujeito era radicalmente livre e, ora com outros, que ele era determinado por condições sociais. Nós descobríamos que era preciso procurar libertar tudo que se esconde por trás do uso aparentemente simples do pronome "eu" (je). O sujeito: uma coisa complexa, frágil, de que é tão difícil falar, e sem a qual não podemos falar (FOUCAULT, 2002, p. 330-331).

Pode-se dizer, a posteriori, que essa entrevista serve como um prelúdio à pesquisa que Foucault empreenderá no ano seguinte, durante o curso de 1982 no Collège de France, intitulado A Hermenêutica do Sujeito. Segundo Frédéric Gros ${ }^{2}$, este curso tem uma singularidade especial. As aulas foram prolongadas e separadas por um intervalo, tornando-se um laboratório vivo, com menos exposição de resultados oriundos de um trabalho anterior, em proveito de uma nova forma de ensino. As aulas se constituíram em leitura e comentário literal de diversos textos escolhidos e introduzidos durante o desenvolvimento do próprio curso. Neste sentido, a composição do curso tornou-se empírica e não-sistemática, e conduzida passo a passo num incessante movimento de vai-e-vem, que, acrescentese, não foi novo na França, mas sim retomou o estilo dos seminários proferidos por Jacques Lacan, onde o público era convocado a refletir, formular questões e acrescentar suas contribuições ou críticas.

Enfim, tento trazer um tipo de material ou fazer certas referências que, de ordinário, mais dificilmente têm lugar em um curso. Gostaria de aproximar um pouco este procedimento do que poderia ser um seminário. Porém, em um seminário isto implica que haja algumas respostas, ou questões-respostas. No momento, por exemplo, há pessoas que gostariam de colocar questões, sejam elas puramente técnicas, sejam questões gerais acerca do sentido da minha exposição? Sim? (FOUCAULT, 2004, p. 231).

Talvez a tentativa de Foucault neste curso fosse retomar o estilo complexo do ensino de Lacan para empreender uma pesquisa de um modo que exprimisse a própria complexidade do sujeito. Vale ressaltar que Lacan teve apenas um aparelho de ensino que foi o seu Seminário. Segundo Miller (2003), a existência de trinta anos do Seminário de Lacan talvez tenha contribuído para fixar este modelo de ensino na França. A

FOUCAULT, 2004, p. 613-661. 
radicalidade desse modelo na tradição europeia de curso do tipo magistral pode ser de difícil apreensão para o leitor brasileiro habituado à informalidade de nossas salas de aula - sobretudo no âmbito das Ciências Humanas, onde o termo serve hoje para designar meras apresentações de trabalhos dos alunos. O seminário, deve-se lembrar, consiste numa longa exposição de um tema que, num segundo momento, será aberto a comentários e debates com os alunos. Desse modo, neste curso de Foucault há uma aproximação direta com o ensino de Lacan, não apenas devido ao modo de exposição, mas principalmente pela natureza do tema abordado.

Trata-se, neste curso/seminário, de remeter à história o problema "sujeito e verdade" a partir de uma noção grega de epimeléia heautoû, traduzida pelos latinos em cura si. Epimeléia heautoû refere-se ao cuidado de si mesmo, ou seja, ao ocupar-se consigo mesmo. Por trás desta noção há um determinado sujeito, o sujeito do conhecimento. Por um lado, o conhecimento do sujeito e por outro o conhecimento do sujeito por ele mesmo, que originariamente foi colocado pela fórmula socrática do "conhece-te a ti mesmo", a famosa prescrição délfica gnôthi seautón. Para Foucault, essa é a fórmula original sobre a questão e relação entre sujeito e verdade. Esse termo está subordinado em relação à expressão "cuida de ti mesmo" (epimeléia heautô̂), como uma de suas formas, uma de suas aplicações. Para Foucault, a epimeléia heautoû constituirá um princípio fundamental para caracterizar a cultura grega, helenística e romana.

Parece-me que a aposta, o desafio que toda história do pensamento deve suscitar, está precisamente em apreender o momento em que um fenômeno cultural, de dimensão determinada, pode efetivamente constituir, na história do pensamento, um momento decisivo no qual se acha comprometido até mesmo nosso modo de ser de sujeito moderno (FOUCAULT, p. 13, [1982], 2004).

Lacan empreendeu durante muitos anos uma pesquisa que teve como objetivo demarcar a diferença entre o sujeito do conhecimento e o sujeito da psicanálise, principalmente pelo fato de que a natureza do sujeito do conhecimento é o desconhecimento de sua própria verdade. Tentaremos demonstrar que, no entanto, a verdade do sujeito da psicanálise é negativa (não tem uso) para o conhecimento e impossível de se inscrever no discurso dos universais.

Alguns poderão dizer que deste último parágrafo se pode recuperar uma das críticas de Foucault à psicanálise em relação à verdade, 
que aparece no livro A Vontade de Saber. Mas, se lançada à psicanálise, parece-nos que esta crítica visa em especial a Freud, que para Foucault refunda a verdade do sujeito como coisa sexual, mantendo desta forma a relação entre poder e verdade através de um dispositivo de aliança que inclui a lei do desejo, o complexo de Édipo, o matrimônio, a relação entre pais e filhos; e, por outro lado, também por um dispositivo de sexualidade como sensações do corpo, economia sexual, e uso dos prazeres. Trata-se de uma produção de sexualidade como discurso, como produção de uma relação entre saber e poder. Nesse sentido, o poder do qual se quer apoderar é o próprio discurso sobre a sexualidade enquanto dispositivo de produção de subjetividade.

Não se pode negar que Freud foi um defensor até a morte da lei do pai, enquanto instância de instauração da subjetividade que se dá pelo laço social de seus irmãos pela cumplicidade no assassinato do próprio pai. O Édipo é um retorno do recalcado do assassinato do Totem e Tabu, como a passagem da aliança estabelecida entre os membros de uma família, através da estrutura do mito, ou seja, do universal para o particular ou do público para o privado, como queiram. A publicação em 1939 de um de seus últimos trabalhos - Moisés e o monoteísmo - é um ápice desta reivindicação. Podemos realizar uma alusão ou um paralelo entre os trabalhos de Foucault e de Freud, na medida em que ambos questionam o modo como se deu a constituição do sujeito na história. Assim como em Foucault, em Freud também se pode observar um questionamento sobre a origem histórica da produção dos sujeitos, da constituição do que ele elabora como Édipo, como sujeito da lei do incesto. Para Freud, a problemática do sujeito também estava ligada a uma moral judaico-cristã, por sua vez, procedente do próprio nascimento da religião judaica.

A hipótese de Freud, baseada em trabalhos arqueológicos sobre a descoberta do código de Hamurábi, e do historiador judeu Ernest Selin sobre a origem da religião judaica, era de que Moisés foi um egípcio seguidor de uma religião monoteísta imposta no Egito pelo Faraó Amenófis IV, surgida a partir do politeísmo. Este Faraó teria estabelecido como a religião do Estado a forma exclusiva de adoração do Deus-Sol. Moisés teria sido um sacerdote egípcio e não um hebreu. Segundo Freud, a fim de salvar a religião de Aton, o Deus-Sol, após a morte de Amenófis IV, Moisés se pôs à frente de uma tribo semítica oprimida libertando-os e criando uma nova nação. Algum tempo depois Moisés foi assassinado pelo seu próprio povo. De um ponto de vista psicanalítico, a ascensão do cristianismo é nada mais que a reemergência disfarçada do assassinato de Moisés, e o 
próprio judaísmo tem suas origens no eterno retorno do assassinato préhistórico de Totem e Tabu. Em outras palavras, o assassinato de Cristo e de Moisés é, em nível inconsciente, uma repetição.

Pode-se afirmar que se trata de uma aproximação ambivalente entre Freud e Foucault, na medida em que a crítica de Foucault se endereça justamente a este ponto em que Freud tenta salvar um dispositivo de aliança baseado na lei do pai. No entanto, o que está em jogo não é o resgate de uma moral judaico-cristã, que se poderia aludir a motivos de Freud em relação a sua origem judia. Dessa interpretação, ponto de ambivalência nesta comparação, se poderia afirmar que Freud, ao salvar o pai, em outras palavras, visava salvar a si mesmo enquanto judeu. No entanto, não são estes seus objetivos; tratava-se antes de justificar um saber fundamental da sua prática, uma bússola de orientação, em que o mito advém no lugar disso que mais tarde se denominaria, com Lévi-Strauss, as estruturas elementares do parentesco. A interpretação freudiana do mito do Édipo visa demonstrar a própria estrutura do inconsciente do retorno do recalcado. Deste modo, o que está colocado na interpretação do mito é um pilar fundamental da psicanálise, a própria noção de inconsciente. Portanto, o que Freud tenta realizar com o mito do Totem e Tabu, com o mito do Édipo e com a teoria sobre a origem do judaísmo é a própria estrutura do inconsciente. A partir desse ponto pode-se introduzir o papel da releitura da psicanálise que Lacan empreendeu nos anos 50 sob o viés estruturalista, e demonstrar um paradoxo da crítica de Foucault.

Em As Palavras e as Coisas, Foucault realiza uma arqueologia das Ciências Humanas onde a Psicanálise ocupa um lugar privilegiado. Enquanto outras ciências humanas realizaram sua fundação num saber que, segundo um velho projeto positivista, visa ser verdadeiramente científico, a psicanálise se manterá mais próxima de uma função crítica e do que se denominará uma contraciência. Para Foucault, esse privilégio está relacionado ao fato de que enquanto as outras ciências vão ao encontro da representação, a psicanálise avança justamente para transpor o espaço do representável, em direção à função da linguagem e da significação no interior das práticas discursivas. A ideia de inconsciente enquanto lugar inacessível a todo conhecimento científico, a toda apreensão contínua em termos de significação, coloca a psicanálise neste lugar privilegiado de uma contraciência.

Sabe-se como psicólogos e filósofos denominaram tudo isso: mitologia freudiana. Era realmente necessário que este empenho de Freud assim 
lhes parecesse; para um saber que se aloja no representável, aquilo que margeia e define, em direção ao exterior, a possibilidade mesma da representação não pode ser senão mitologia (FOUCAULT, 1999, p. 519).

Ao que parece, Foucault detinha uma leitura precisa do lugar do inconsciente na psicanálise: e o mito era uma forma de tocar o que Freud não havia conseguido, e que Lacan mais tarde denominará a estrutura própria do inconsciente. O inconsciente é o lugar inacessível a todo conhecimento teórico do homem. Neste ponto, a psicanálise:

[...] avança para transpor a representação, extravasá-la do lado da finitude e fazer assim surgir, lá onde se esperavam as funções portadoras de suas normas, os conflitos carregados de regras e as significações formando sistema, o fato nu de que pode haver sistema (portanto, significação), regra (portanto, oposição), norma (portanto, função) (FOUCAULT, 1999, p. 518).

Este parágrafo exemplifica o quanto Foucault estava atento para a função do mito na obra freudiana. Sua função foi representar a estrutura que Freud não conseguiu elaborar. Ora, resta perguntar por que este lugar da lei da estrutura, enquanto lei do pai, mito do Édipo ou lei do desejo ganha uma conotação negativa em A Vontade de Saber, se justamente é nos limites dessa lei, no seu atravessamento - ou, como prefere Foucault, no seu extravasamento - que se dá o limite do conhecimento e de uma subjetivação universal. Trata-se para a psicanálise de levar os analisandos em direção a esta impossibilidade do conhecimento de abordar algo que escapa aos limites da representação, do saber e do poder, ou seja, do mito.

É por isso que a psicanálise encontra nesta loucura por excelência - a que os psiquiatras chamam esquizofrenia - o seu íntimo, o seu mais invencível tormento: pois nesta loucura se dão, sob uma forma absolutamente manifesta e absolutamente retraída, as formas de finitude em direção à qual, de ordinário, ela avança indefinidamente (e no interminável), a partir do que lhe é voluntária-involuntariamente oferecido na linguagem do paciente (FOUCAULT, 1999, p. 520).

É na experiência da loucura que está a impossibilidade do conhecimento científico, haja vista a singularidade do sentido para o indivíduo e a impossibilidade do laço social pelo delírio, pelo fato de que o saber que está em jogo na esquizofrenia não serve para todos, não se 
insere na ordem do universal. Ou seja, o delírio do paranoico é uma verdade construída por um determinado sujeito, e seu sentido não serve para outro sujeito paranoico. Pode-se tomar o delírio como uma solução particular, enquanto o sintoma, advindo da lei do pai, como uma solução normativa e universal. Neste sentido, o íntimo da psicanálise, como aponta Foucault, é algo que do sujeito se descola da sua própria subjetividade enquanto produto de saber, algo que a significação e a representação não conseguem capturar como sentido, como sujeito do conhecimento. $\mathrm{O}$ delírio enquanto saber do delirante não serve, portanto, ao universal.

O problema crucial da relação entre Foucault e a psicanálise aparece no não-reconhecimento de alguns psicanalistas à crítica que se pretende estabelecer em $A$ Vontade de Saber. Por que não nos reconhecemos nesta crítica à psicanálise? Porque em relação ao problema do mito, da lei do desejo e do sujeito, Lacan realizou avanços consideráveis no início do seu ensino, e, outros radicais, a partir do início dos anos 70. No último ensino de Lacan, o Édipo e o pai tomam um outro lugar na psicanálise, não mais como fundadores da subjetividade enquanto norma, mas como fundadores de uma determinada subjetividade que se remete a um determinado tempo histórico, o de Freud. O mito do Édipo está no último ensino de Lacan como um outro nome do delírio e adquire a função de suplência a um impossível de saber, que exprime uma inacessibilidade através do conhecimento de si. Deste modo, haveria uma decalagem entre as críticas de Foucault dirigidas à psicanálise em meados dos anos 70 e as soluções encontradas por Lacan nesta mesma época.

A saída que propomos para entender esta decalagem das críticas de Foucault em A Vontade de Saber está na forma de ensino e transmissão que Lacan empreendeu, ou seja, em seus seminários. Há inúmeras referências nos seminários publicados de Lacan sobre as obras publicadas de Foucault. Por exemplo, na aula de 26 de fevereiro de 1969, do último seminário publicado na França sob o título D'un Autre à l'autre, Lacan faz menção a uma aula de Foucault proferida na Sociedade Francesa de Filosofia, em 22 de fevereiro de 1969, na qual este último tece um comentário sobre o movimento de retorno que Lacan empreendeu aos textos freudianos.

Por "retorno a", o que se pode entender? Acredito que se pode designar dessa maneira um movimento que tem sua própria especificidade e que caracteriza justamente as instaurações de discursividades. Para que haja retorno de fato, é preciso inicialmente que tenha havido esquecimento, não esquecimento acidental, não encobrimento por alguma 
incompreensão, mas esquecimento essencial e constitutivo (FOUCAULT, 2001, p. 284).

Parece que não foi possível para Foucault acompanhar diretamente o ensino de Lacan, tendo em vista que este não se dava por meio de uma publicação periódica, sendo o resultado deste ensino publicado, em parte, pós-morte de ambos os autores. O acompanhamento das ideias de Lacan por Foucault deu-se de forma indireta, pelos efeitos provocados em seus alunos.

Quero dizer: eu deveria interrogar-me sobre o que faço. No outro, deveria interrogar Lacan e saber o que, efetivamente, na prática, em um campo conceitual como o da psicanálise, e da psicanálise lacaniana, concerne, de um modo ou outro, a esta problemática do sujeito, à relação do sujeito consigo mesmo, à relação do sujeito com a verdade, etc., tal como foi historicamente constituída nesta longa genealogia que tento recompor, desde Alcebíades até Santo Agostinho (FOUCAULT, 2005, p. 232).

Ou seja, de forma indireta, Foucault reconhece o esforço de Lacan em elaborar a relação entre sujeito, saber e verdade que se dá pela própria subversão do sujeito do conhecimento. Se há um saber sobre o sujeito na psicanálise, esse saber não é para todos, é caso a caso, singular a cada um. Trata-se aqui do próprio retorno $a$, ao que do sujeito é singular e irredutível ao conhecimento, o qual Lacan elaborou, nos anos de 1965 e 1966, como sendo o objeto da psicanálise, o objeto $a$. Se para Sócrates é possível conhecer a si mesmo, para a psicanálise, na sua orientação, há um impossível do sujeito de ser reduzido a qualquer conhecimento. A partir desta relação do sujeito com a impossibilidade de formular um conhecimento de si, ao fim de seu ensino, Lacan elaborará operadores como gozo, real e falasser.

No início, trata-se de um movimento de releitura que Lacan empreende durante quase dez anos aos textos freudianos, ou seja, o retorno $a$, o retorno ao objeto da psicanálise. Isto acontece numa fase que se dá desde seu primeiro seminário sobre Os Escritos Técnicos de Freud (1953-1954) até o seminário sobre Os quatros conceitos fundamentais da psicanálise (1964).

Nos cinco primeiros seminários, Lacan procura fundamentar uma teoria do inconsciente a partir do estruturalismo, bem como a noção de Eu e a constituição do sujeito freudiano da segunda tópica. O Édipo e 
o pai adquirem o estatuto de metáfora, como sendo aquilo que vem no lugar de outra coisa. Uma metáfora para Lacan é definida pelo tropo de linguagem que consiste num significante que vem no lugar de outro significante. Neste sentido, o nome-do-pai adquire o estatuto de metáfora, como um significante que é exterior à cadeia significante e que funda o sujeito do inconsciente, lançando-o para dentro da linguagem. Dizer que um significante é exterior à cadeia implica naquilo que pode nomear a própria cadeia enquanto conjunto, ou seja, o seu nome.

Nesta época, entre 1953 e 1958, e a partir da teoria do estádio do espelho, Lacan elabora a diferença entre o Eu e o sujeito. O Eu se formará a partir da experiência do espelho numa relação imaginária e especular em relação ao outro. Ou seja, o Eu será instituído como um outro. Só depois do estádio do espelho é que poderá advir o sujeito do inconsciente pela passagem do que Lacan denominou os "três tempos do Édipo". A partir dessa experiência se estabelecerá a relação do sujeito com o desejo. O resultado é uma determinada posição em relação à lei que será dividida em três estruturas: as psicoses, as perversões e as neuroses. Este é o momento que Lacan descola o mito da estrutura e elabora a tese de que o inconsciente é estruturado como uma linguagem.

Lacan começa a esboçar uma teoria sobre o objeto $a$, cujo auge aparece no seminário da Angústia a partir da topologia da esfera, do toro, do cross-cap, da garrafa de Klein e da banda de Moebius. O objeto aparecerá neste seminário como aquilo que do sujeito é irredutível ao sentido, e receberá um estatuto topológico numa dialética entre o exterior e o interior. Este ponto do ensino de Lacan é fundamental, uma vez que a partir da formulação da teoria do objeto $a$ se consegue lançar a psicanálise para além do complexo de Édipo. O sujeito irá se constituir enquanto sujeito dividido, como refenda, resultado de uma operação de divisão em relação ao campo do Outro. Esta operação terá como resto um objeto irredutível ao sentido. Se há uma essência do sujeito é essa impossibilidade de acesso ao objeto pela via do saber e da norma fálica relativa ao complexo de Édipo. Na medida em que esse sujeito tenta enfiar esse objeto no campo do significante e nas relações de significação e produção de sentido, o único resultado que obtém é a sua própria angústia. Em outras palavras, os processos de tentativas de subjetivação, disso que dos sujeitos não se insere nos universais, têm como consequência, geralmente, a produção da angústia no sujeito. Esta angústia manifesta-se como estrangulamento na garganta, na tentativa de capturar o próprio nada pela teia dos 
significantes. O sintoma é uma forma de fazer o objeto entrar no campo do sentido, uma resposta à angústia, ao custo de um sofrimento psíquico e físico. Portanto, o sujeito se inscreve num espaço de discurso onde a verdade apenas pode ser meio-dita.

A partir disso, a essência do sexual toma o lugar do impossível de se escrever pela via do significante. Por conseguinte, há um deslocamento da lei do pai para a lei do significante. O significante para Lacan é o que representa um sujeito para outro significante. Ou seja, não existe última significação para o sujeito pela via do conceito. A operação da análise irá do sentido ao sem sentido, do universal do conhecimento ao singular, que Foucault situa de forma precisa em As Palavras e as Coisas. A psicanálise aparece na contramão das outras ciências humanas. Enquanto estas visam uma objetividade e formulação dos universais, da lógica do para todos, estabelecida pela ideia de um sujeito do conhecimento, a psicanálise, por outro lado, funda-se a partir do singular de cada um, pela ideia de inconsciente como o que vem recobrir um saber impossível sobre o sexual. Em outras palavras, não há um significante possível de representar o sujeito, já que ele se funda na relação metonímica da bateria de significantes. Nesta relação, o desejo "é sempre desejo do desejo do outro". O que está por trás da lógica do desejo é justamente que o sujeito do conhecimento nada quer saber: que a relação sexual, algo que garanta a norma do desejo e do sexo, não existe. Neste ponto, é que a lei do pai não funciona. Se funcionasse, não haveria sintomas, justamente pelo fato de que o sintoma é a tentativa de reparar um dano que a lei do pai não consegue obturar.

No seu último ensino, em especial no seminário dos anos de 1975 e 1976, Lacan elaborará uma nova teoria sobre o sintoma em que o mito do Édipo, enquanto fundador da lei do desejo e instaurador da metáfora paterna, será colocado como função de suplência da relação sexual que não existe. E apresentará - neste ponto, há um afastamento claro em relação a Freud - uma nova clínica, a clínica dos nós borromeanos, a clínica do gozo e do sinthoma. Trata-se de uma clínica onde começam a desaparecer algumas pegadas do estruturalismo, principalmente no declínio do complexo de Édipo como fundador da subjetividade. O que Lacan nos apresentará é a existência de outras formas de constituir uma amarração entre os três registros - o real, o simbólico e o imaginário - diferentemente da via da metáfora paterna. Não pretendo aqui precisar estes conceitos, mas indicar historicamente um Lacan para além do Édipo e da metáfora paterna.

Parece que Foucault não teve acesso a este último ensino de Lacan, que aconteceu quase simultaneamente à publicação do primeiro livro 
sobre a História da Sexualidade. A hipótese é que a inacessibilidade das ideias de Lacan estava na forma proposital de transmissão e de ensino: os seus Escritos, que para o autor foram feitos para não ser lidos, e os seus Seminários que adquiriam cada vez mais um caráter esotérico. Ou seja, ao invés de promover uma compreensão mais esclarecedora de suas ideias ao fim de sua vida, Lacan optou, ao contrário, por um obscurecimento cada vez mais radical, uma experiência cada vez mais afastada do sujeito do conhecimento e da compreensão, talvez numa tentativa de exprimir em seu estilo, como nos aponta Foucault, a experiência da própria complexidade do sujeito, a experiência da morte do sujeito do conhecimento.

E parece-me que todo interesse e a força das análises de Lacan estão precisamente nisto: creio que Lacan foi o único depois de Freud a querer recentralizar a questão da psicanálise precisamente nesta questão das relações entre sujeito e verdade. Isto significa que, em termos inteiramente estranhos à tradição histórica desta espiritualidade, seja a de Sócrates, seja a de Gregório de Nissa e de todos os intermediários entre eles, em termos do próprio saber analítico, ele tentou colocar a questão que, historicamente, é propriamente espiritual: a questão do preço que o sujeito tem a pagar para dizer o verdadeiro e a questão do efeito que tem sobre o sujeito o fato de que ele disse, de que pode dizer e disse, a verdade sobre si próprio (FOUCAULT, 2004, p. 40).

Deste modo, a nossa proposta consistiu em aproximar as pesquisas de Foucault e Lacan pela relação que o sujeito mantém entre o saber e a verdade. $\mathrm{O}$ que estes autores tentaram demonstrar em suas pesquisas foi que a relação entre saber e verdade não é algo natural. Para Lacan, o sujeito paga um preço específico ao tentar enfiar a verdade no saber. De certa forma, em Foucault foi justamente o movimento das ciências em geral: afastar a subjetividade e, em última instância, o próprio sujeito, reduzindo assim toda a verdade ao universal do conhecimento. O preço que o sujeito paga para fazer existir a verdade no saber como conhecimento é o seu próprio apagamento, o desconhecimento sobre si, que parece consistir, por excelência, a sua própria verdade.

\section{REFERÊNCIAS}

DOR, J. A-cientificidade da psicanálise. Porto Alegre: Artes Médicas, 1993.

ERIBON, D. Michel Foucault e seus contemporâneos. Rio de Janeiro: Jorge Zahar, 1996. 
FOUCAULT, M. O sujeito e o poder. In: DREYFUS, H.; RABINOW, P. Michel Foucault uma trajetória filosófica. Rio de Janeiro: Forense Universitária, 1995. p. 231-249.

. História da sexualidade: a vontade de saber. São Paulo: Graal, 1998.

. As palavras e as coisas. São Paulo: Martins Fontes, 1999.

Estética: literatura e pintura, música e cinema. Rio de Janeiro: Forense Universitária, 2001.

. Lacan, o "Liberatore" da psicanálise. In:

Ditos e escritos. Rio de Janeiro: Forense Universitária, 2002. p. 329-330.

Problematização do sujeito: psicologia, psiquiatria e psicanálise. Rio de Janeiro: Forense Universitária, 2002.

A hermenêutica do sujeito. São Paulo: Martins Fontes, 2004.

FREUD, S. Moisés e o monoteísmo. Rio de Janeiro: Imago, 1996. p. 13-150. (Edição Standard Brasileira das Obras Psicológicas Completas de Sigmund Freud. v. 23. Publicado originalmente em 1939 [1934-1938]).

LACAN, J. Escritos. Rio de Janeiro: Jorge Zahar, 1998.

. Le sinthome. Le Séminaire livre XXIII. Paris: Seuil, 2005.

. D‘un Autre à l'autre. Le Seminaire livre XVI. Paris: Seuil, 2006.

MILler, J-A. O Rouxinol de Lacan. Carta de São Paulo, São Paulo, v. 10, n. 5, p. 18-32, 2003.

PRADO FILHO, K. Michel Foucault: uma história política da verdade. Florianópolis: Insular, 2006.

Recebido: 10/12/2008

Received: $12 / 10 / 2008$

Aprovado: 04/03/2009

Approved: 03/04/2009 